\title{
Endoscopic-Assisted Microvascular Decompression of Ectatic Vertebral Artery for Hemifacial Spasm: Operative Video and Technical Nuances
}

\author{
James K. Liu ${ }^{1}$ Vincent N. Dodson ${ }^{1}$ \\ ${ }^{1}$ Department of Neurological Surgery, Center for Cerebrovascular \\ and Skull Base Surgery, Rutgers University, New Jersey Medical \\ School, Neurological Institute of New Jersey, RWJ Barnabas Health, \\ Livingston and Newark, New Jersey, United States
}

\begin{abstract}
Address for correspondence James K. Liu, MD, Department of Neurological Surgery, Rutgers University, New Jersey Medical School, 90 Bergen Street, Suite 8100, Newark, NJ 07103, United States (e-mail: james.liu.md@rutgers.edu).
\end{abstract}

J Neurol Surg B 2019;80(suppl S3):S312-S313.

\begin{abstract}
Keywords

- microvascular decompression

- endoscopic assistance

- hemifacial spasm

- ectatic vertebral artery

In this operative video atlas manuscript, the authors demonstrate the operative nuances and surgical technique for endoscopic-assisted microvascular decompression of a large ectatic vertebral artery causing hemifacial spasm. A retrosigmoid approach was performed and a large ectatic vertebral artery was transposed away from the root exit zone of cranial nerve VII (-Fig. 1). The lateral spread response disappeared, signifying adequate decompression of the facial nerve (-Fig. 2). The use of endoscopicassistance during the microsurgical decompression was very useful to confirm the origin and also the resolution of neurovascular conflict. Postoperatively, the patient experienced immediate resolution of hemifacial spasm with normal facial nerve and hearing function. Written consent was obtained from the patient to publish videos, photographs, and images from the surgery.

The link to the video can be found at: https://youtu.be/RIMz44uCDCw.
\end{abstract}

Conflict of Interest

None.

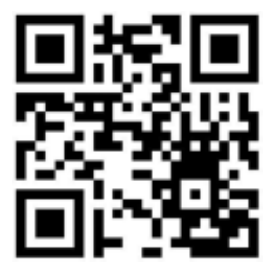

received

March 30, 2019

accepted

April 2, 2019

published online

April 30, 2019 www.thieme.com/skullbasevideos

www.thieme.com/jnlsbvideos
License terms

(c) $(1) \risingdotseq$
DOI https://doi.org/

10.1055/s-0039-1688807. ISSN 2193-6331. (c) 2019 Georg Thieme Verlag KG Stuttgart · New York

(1) 


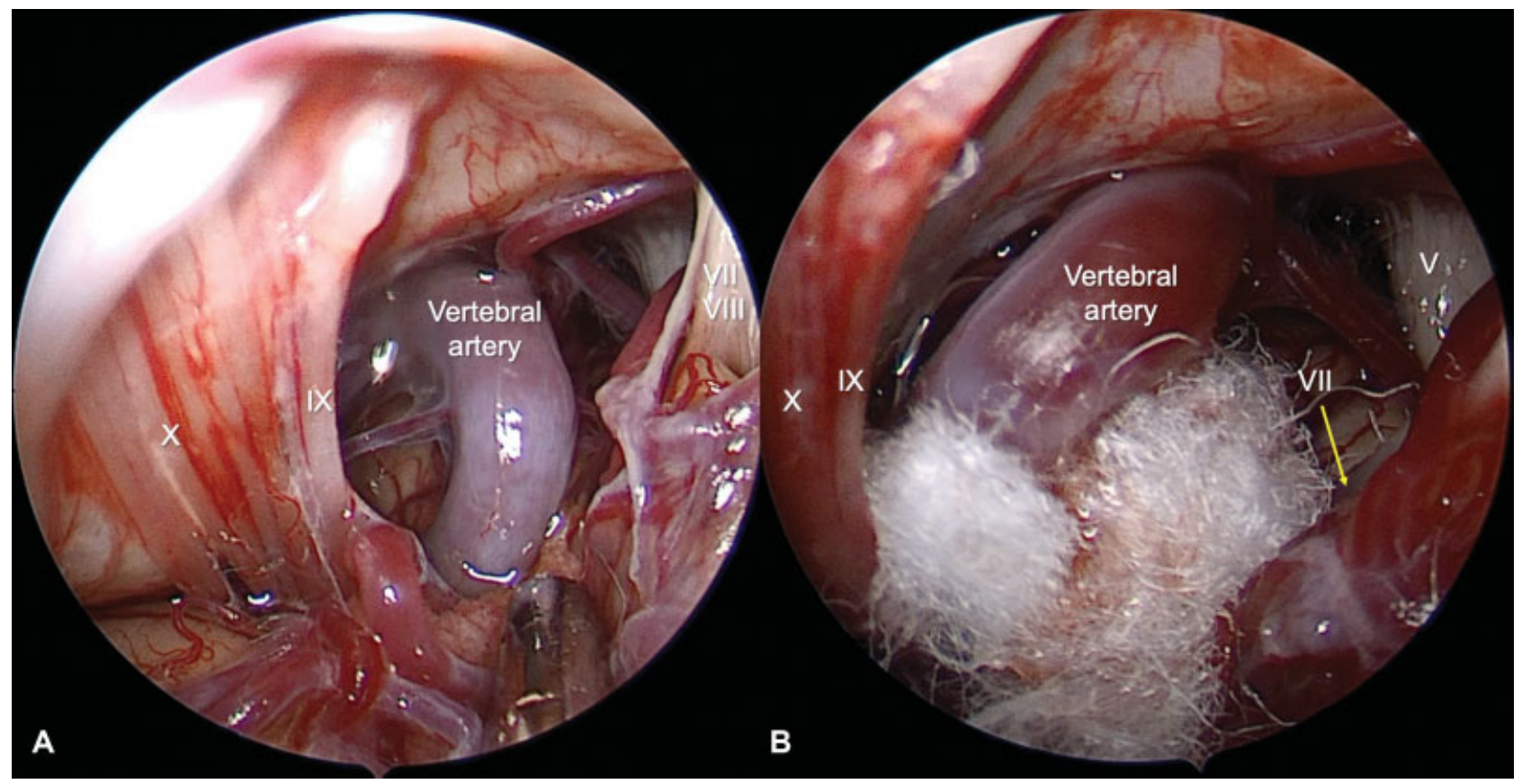

Fig. 1. Intraoperative endoscopic photographs of a left retrosigmoid approach for microvascular decompression of an ectatic vertebral artery compression of the facial nerve. Views of the anatomy before (A) and after (B) decompression are visualized. Placement of Teflon sponges separated the ectatic vertebral artery from the root exit zone of the 7th cranial nerve (VII).

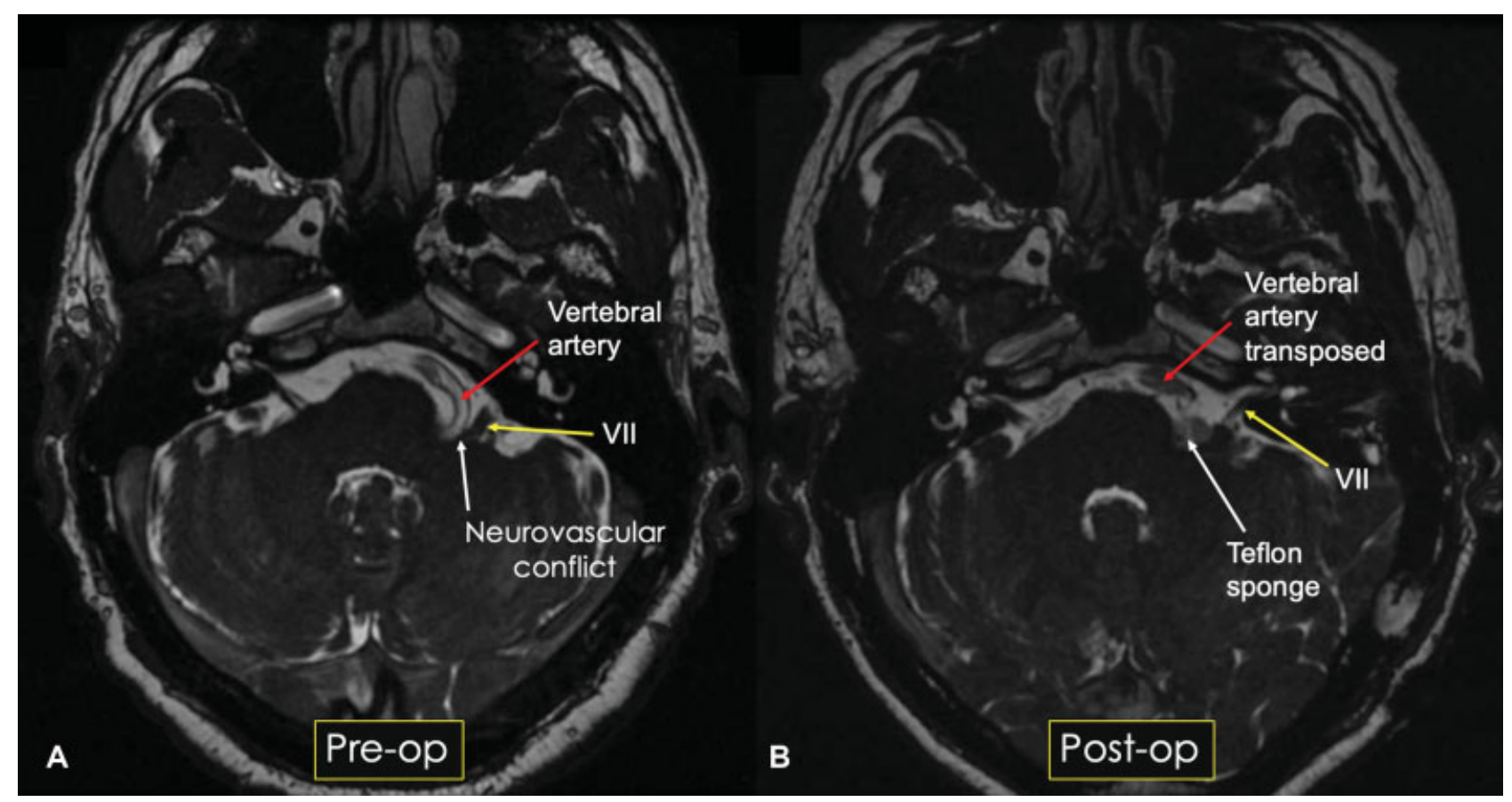

Fig. 2. (A) Preoperative FIESTA MRI demonstrates a large, ectatic vertebral artery compressing the root exit zone of the 7th cranial nerve. (B) Postoperative FIESTA MRI shows transposition of the vertebral artery after microvascular decompression of the 7th cranial nerve. MRI, magnetic resonance imaging. 